\title{
Pain management in functional gastrointestinal disorders
}

\author{
ANTONIO VIGANO MD, EDUARDO BRUERA MD
}

\begin{abstract}
A VIGANO, E BRUERA. Pain management in functional gastrointestinal disorders. Can J Gastroenterol 1995;9(2):85-90. Pain is a common feature in functional gastrointestinal disorders (FGID). An abnormally low visceral sensory threshold, as well as a number of central, spinal and peripheral pain-modulating abnormalities, have been proposed for this syndrome. Clinical aspects of pain associated with irritable esophagus, functional dyspepsia, biliary dysmotility, inflammatory bowel syndrome and proctalgia fugax are reviewed. Because of its unclear pathophysiology, pain expression is the main target for the successful assessment and management of symptomatic FGID. The sensory, cognitive and affective components of pain intensity expression need to be addressed in the context of a good physician-patient rapport. A multidisciplinary team approach is ideal for the smaller subset of patients with severe and disabling symptoms. Although pharmacotherapy may target specific functional disorders, the role of behavioural techniques and psychotherapy appears much more important for pain management in FGID. Functional performance and quality of life improvement, rather than pain intensity, are the main therapeutic goals in these patients.
\end{abstract}

Key Words: Functional gastrointestinal disorders, Pain assessment and management, Quality of life

\section{Traitement de la douleur dans la maladie gastro-intestinale fonctionnelle}

RÉSUMÉ : La douleur est une caractéristique fréquente des troubles gastrointestinaux fonctionnels (TGIF). Un seuil sensoriel viscéral anormalement bas, de même qu'un nombre d'anomalies sensorielles au niveau central, spinal et périphérique ont été avancées pour expliquer ce syndrome. Les aspects cliniques de la douleur associés à l'oesophage irritable, à la dyspepsie fonctionnelle, à la dysmotilité biliaire, au syndrome inflammatoire intestinal et à la proctalgie fugace sont passés en revue. Â cause de sa physiopathologie imprécise, l'expression de la douleur est la principale cible d'une évaluation et d'un traitement réussis des

voir page suivante Alberta

Correspondence: Dr Antonio Vigano, Fellow in Clinical Research, Palliative Care Program, Edmonton General Hospital, 11111 Jasper Avenue, Edmonton, Alberta T5K OL4. Telephone (403) 482-8531

Received for publication July 14, 1994. Accepted August 15, 1994
A international working A panel recently defined functional gastrointestinal disorders (FGID) as a "variable combination of chronic or recurrent gastrointestinal symptoms not explained by structural or biochemical abnormalities. FGID include symptoms attributed to the pharynx, esophagus, stomach, biliary tree, small and large intestine or anorectum" (1). The common symptom among FGID is pain, while other specific symptoms characterize the different functional symptom complexes.

Irritable bowel syndrome (IBS) is the prototype of FGID in terms of prevalence, physiopathology, clinical findings and therapeutic opportunities (2). The description of IBS is beyond this paper's purposes. However, IBS will be considered a model to describe the current understanding of the physiopathology and treatment of pain in FGID.

\section{PHYSIOPATHOLOGY}

In an attempt to understand the causes and the mechanism of pain in IBS, the features of visceral sensation and clinical evidences for altered pain perception in the gastrointestinal tract have been extensively reviewed. Visceral sensation can be subdivided into two functional categories: nonpainful conscious sensation which informs the individual about the state of the gastrointestinal tract with sensations of full- 
TGIF symptomatiques. Les composantes sensorielles, cognitives et affectives qui caractérisent l'expression de la douleur dans son intensité doivent être abordées dans le contexte d'un bon rapport médecin-patient. Une approche pluridisciplinaire est idéale chez un sous-groupe de patients plus restreint atteints de symptômes graves et invalidants. Bien que la pharmacothérapie puisse s'attaquer à certains troubles fonctionnels spécifiques, le rôle de techniques comportementales et de la psychothérapie semble beaucoup plus important pour le traitement de la douleur associée aux TGIF. L'amélioration du rendement fonctionnel et de la qualité de vie plutôt que le soulagement de la douleur sont donc les principaux objectifs thérapeutiques chez ces patients.

ness, hunger, satiety and nausea; and painful visceral sensation which informs the individual about potentially noxious events such as irritation of the mucosa or serosa, gross distension of the viscus, torsion or traction on the mesentery, forceful contractions and ischemia. Nociceptors have not been identified in viscera; noxious and nonnoxious stimuli are identified within the central nervous system (CNS) by their intensity of discharge. Furthermore, there is no specific pathway for visceral afferents in the spinal cord. Visceral and somatic inputs converge in the same second-order neurons of somatic sensory. Subsequently, visceral pain is poorly localized and is accompanied by autonomic and somatic reflexes as frequently seen in FGID.

Pain modulation is accomplished by central, spinal and peripheral mechanisms. The central structures play an important role in the processing of the sensory experience of pain. Descending inhibitory pathways can be activated by endorphins from the periaqueductal grey area of the brain. The convergence of various sensory inputs into the same second-order neuron within the spinal cord can facilitate or inhibit the pain transmission as suggested in the gate-control theory by Melzak and Wall. Finally, inflammatory mediators, neuropeptides released from afferent terminals (antidromic nerve stimulation) and smooth muscle tone may modulate the sensory function of visceral receptors (3).

It has become apparent that pain in FGID is related to an abnormally low visceral sensory threshold (4). However, it is still unclear where in the pain modulating mechanisms the deregulation may take place.

An increased visceral sensitivity has been shown by intraluminal balloon distension of the stomach in functional dyspepsia. Similar findings have been extensively reported in the colon and in the esophagus for IBS patients. The distension-induced pain was never related to an abnormal visceral compliance (5). In IBS patients, stressful stimuli seem to influence intestinal motility and pain perception to a greater extent than in normal individuals. Conversely, those gut disturbances may influence the central nervous system. IBS patients with balloon distension in the colon experienced pain at many extracolonic sites such as the shoulder, back and thigh. These findings may suggest an alteration in visceral pain discrimination and a facilitation of referred pain mechanisms (3).

Pain in FGID may be partly caused by a hypoactive CNS antinociceptive system. A decreased level of cerebrospinal fluid beta-endorphins has been found in patients with long-lasting functional lower abdominal pain (6). However, the pain sensitivity for ischemia in this population was not found to be significantly increased as previously shown for upper abdominal pain in functional dyspepsia. The possible effect of a low level of beta-endorphins on pain threshold may be enhanced or counterbalanced by neuropsychological mechanisms such as level of attention, anxiety, depression and mood.

Even though the role of psychological factors in the etiology of FGID is still unclear, a common feature of these conditions is the frequent association with psychiatric illness, especially mood changes, anxiety or somatization disorders (7). Life threatening events, loss of a job or loved one, long-standing stress and severe emotional upset appear to precede the development of functional abdominal pain more frequently than the onset of organic gastrointestinal disease (8). Furthermore, a history of sexual and physical abuse was particularly common in women suffering from FGID (9). Those events also seem to enhance symptom reporting and health care utilization especially for pain management. A psychological similarity has been found between persons having IBS who do not consult a physician and normal individuals (10). So far, psychosocial disturbances appear to influence, rather than directly cause, the greater symptomatic and physiological response to stressor in FGID patients compared with normal individuals (1).

\section{CLINICAL ASPECTS OF THE PAIN SYNDROMES}

A description of all the symptoms characterizing FGID with the related diagnostic approaches is beyond the scope of this paper. Only pain manifestations in the major FGID, such as irritable esophagus, functional dyspepsia, biliary dysmotility, IBS and proctalgia fugax, will be reviewed.

Chest pain resulting from irritable esophagus may fall into three clinical manifestations: pyrrhosis or heart burn; odynophagia or pain on swallowing; and spontaneous pain. While pyrrhosis or odynophagia may easily be attributed to an esophageal disorder, spontaneous chest pain of esophageal origin is more difficult to diagnose. In the absence of other specific symptoms, besides the irritable esophagus syndrome, one should consider gastrointestinal (eg, peptic ulcer disease), cardiac (eg, angina pectoris) or musculoskeletal (eg, costochondritis) organic disease (11).

Burning or gnawing pain at the epigastrium is present in the majority of patients suffering from functional dyspepsia. Because of the frequent overlapping of functional dyspepsia 
symptoms with those of classic peptic ulcers, ulcer and nonulcer dyspeptics have been identified. In nonulcer dyspepsia, eating-related pain is frequent, while nocturnal pain, male preponderance and family history appear to be less important than in peptic ulcer disease (12).

Epigastric or right hypogastric pain simulating the biliary colic of gallstones, but without identifiable disease, may be caused by disordered motility of the sphincter of Oddi. Pain in biliary dysmotility may be precipitated by fatty foods or codeine but is often spontaneous and sometimes nocturnal.

Abdominal pain in IBS is generally colicky and dull. Its location may be over the anatomical location of the colon or extracolonic. The spasmodic attacks may start during or right after a meal, but the acute phase is mostly reported 1 to $1.5 \mathrm{~h}$ after eating. The severity of abdominal discomfort may be related to different kinds of foods, even though exacerbation and relief of IBS pain are variable in different individuals. Passage of flatus and bowel movements generally decrease the symptomatology (2).

Finally, severe pain occurring around the anus during defecation, after coitus or spontaneously in the absence of organic diseases is the hallmark of proctalgia fugax. This pain recurs in paroxysms during the day and night, ceasing without residue in less than 10 to 20 mins. During these attacks syncope, priapism and a tight, tender band across the lower rectum may be observed (13).

\section{ASSESSMENT}

Pain production in FGID may be related to three stages: nociception (concerning the genesis of the noxious stimulus); perception (related to the central, spinal and peripheral modulations of the nociceptive input); and expression (representing the final processing of the sensory experience of pain). Because the first and second stages cannot be assessed or monitored clinically, treatment will be aimed to decrease the pain expression.

It has been shown in both acute and chronic syndromes that the intensity of
TABLE 1

Unidimensional pain assessment

Problems:

Lack of disciplined assessment

Misuse of pharmacological and

nonpharmacological interventions

Over-use of antinociceptive interventions and underuse of other interventions

Increased drug-related toxicity

TABLE 2

Multidimensional pain assessment

\begin{tabular}{ll}
\hline $\begin{array}{l}\text { Pain } \\
\text { syndrome }\end{array}$ & Neuropathic/lncidental \\
Social & Family/Financial/Cultural \\
Drug & Dose/Rapid tolerance?/ \\
& Toxicity \\
Patient & Renal function/Psychological \\
& distress, coping history/ \\
& Addiction/Cognition \\
& (hypoalert/hyperalert?)/ \\
& Spiritual \\
\hline
\end{tabular}

Classic model

Cancer pain syndrome Chronic benign pain syndrome

\begin{tabular}{|c|c|}
\hline Pain relief & Functional improvement \\
\hline & Emerging model \\
Cancer pain syndrome & Chronic benign pain syndrome \\
\hline Pain relief & Functional improvement \\
\hline
\end{tabular}

Figure 1) The classic and emerging model of the cancer pain syndrome and the chronic benign pain syndrome

pain can be easily measured by subjective assessments. Numerical, verbal and visual scales provide an idea of the 'quantity' of the patient's pain expression. Those tools may be assimilated to a sphygmomanometer or to a glucometer that measures blood pressure or glycemia, respectively, by unidimensional and standardized criteria.

The intensity of pain, however, cannot be considered a simple entity. A unidimensional approach considers pain expression a direct manifestation of nociception (similar to a blood pressure reading in hypertension or blood glucose determination in diabetes mellitus). Such simplified assessment assumes that pain is always what the patient defines as pain, and that the intensity the patient reports is $100 \%$ nociception. This approach may lead to lack of a disciplined assessment of the different dimensions of pain expression, to misuse/overuse of antinociceptive interventions and to underuse of nonpharmacological interventions (Table 1 ).

Pain is "a multidimensional experience with sensory as well as cognitive and affective components modulated by environmental contingencies..." (14). Functional disorders from illness, level of cognitive function, positive history of addiction/alcoholism, drug tolerance and toxicity, environmental stressors, psychiatric illness, impairment in daily and social function, unconscious secondary gain, somatization and other illness coping behaviours may contribute to the final 'construct', which is the pain intensity expression.

The multidimensional evaluation of physical, social, psychological and spiritual components of pain is necessary for the management of both chronic benign and malignant syndromes. Table 2 reports some of those dimensions. Therefore, a multidisciplinary team approach is useful, particularly for patients with severe and disabling symptoms.

\section{MANAGEMENT}

Once diagnosis and a good rapport between the physician and the patient have been established, an accurate setting of goals and instruments for pain control in FGID is possible. As shown in 
TABLE 3

Comparison of cancer pain with chronic benign pain

\begin{tabular}{|c|c|}
\hline Cancer pain patients & Chronic benign pain patients \\
\hline Short survival & Long survival \\
\hline $\begin{array}{l}\text { Multiple severe symptoms (cachexia, } \\
\text { dyspnea, nausea) }\end{array}$ & Pain-only symptom \\
\hline Multiple drugs & Few drugs \\
\hline Frequent cognitive failure & Somatization, addiction, affective problems \\
\hline $\begin{array}{l}\text { Mechanism: somatic, visceral, } \\
\text { neuropathic }\end{array}$ & Frequent neuropathic mechanism \\
\hline Palliative care & Seen by chronic pain clinics \\
\hline Cancer pain & Chronic benign pain \\
\hline Mechanism of pain evident & Mechanism less evident and predictable \\
\hline $\begin{array}{l}\text { Assessment of pain intensity } \\
\text { (ill patients) }\end{array}$ & Assessment of functional status (pain as illness) \\
\hline $\begin{array}{l}\text { Focus on pain intensity and aggravating } \\
\text { factors }\end{array}$ & $\begin{array}{l}\text { Discourage pain behaviour (maladaptive), } \\
\text { reinforce rehabilitation }\end{array}$ \\
\hline Opioids main treatment & $\begin{array}{l}\text { Discontinue all possible drugs (antidepressants, } \\
\text { NSAIDs, opioids) }\end{array}$ \\
\hline $\begin{array}{l}\text { Nonpharmacological treatments } \\
\text { rare }\end{array}$ & $\begin{array}{l}\text { Emphasis on increased control (TENS, relaxation, } \\
\text { etc) }\end{array}$ \\
\hline
\end{tabular}

NSAIDs Nonsteroidal anti-inflammatory drugs; TENS Transdermal electrical stimulation

TABLE 4

Guidelines for the opioid use in chronic nonmalignant pain

Establish the medical diagnosis underlying the pain

Consider a recent/remote history of substance abuse

Exclude any benefit from first line nonopioid analgesic and adjuvant drugs

Identify only one physician to prescribe opioids

Employ the World Health Organization 'analgesic ladder' principles for cancer pain management

Avoid short-acting (eg, meperidine) and agonist-antagonist (eg, pentazocine) opioids

Identify the dose associated with meaningful partial analgesia and no opioid toxicity compromising comfort or function

Advance to a higher step on the analgesic ladder whenever the previous has been unsatisfactory

Whenever a strong opioid is indicated, the oral morphine is convenient for titration. The starting dose should be $10 \mathrm{mg}$ by mouth every $4 \mathrm{~h}$. This dose should be increased once or twice weekly by 25 to $50 \%$ until the desired effect is achieved

Include with 'around the clock' administration, the prescription of extra opioid doses as required to treat breakthrough pain

If there are no contraindications (eg, features suggesting abuse) the patient on a stable and effective dose of short-acting morphine preparation should be switched to a long-acting one (every 8 to $12 \mathrm{~h}$ )

Parenteral administration of opioids is strongly discouraged

Define a clear 'contract' between the prescribing physician and the patient regarding opioid management

Reassess frequently the patient on opioids to evaluate analgesic efficacy and toxicity, physical and psychological function and the occurrence of drug abuse-related behaviours

Figure 1, pain relief and functional improvement have been proposed as the main outcome measurements of the patient with the cancer pain syndrome and the chronic benign pain syndrome, respectively (14). The cancer paradigm proposed mostly pharmacological approaches based on a need to decrease pain expression, while chronic benign pain management emphasized non- pharmacological treatments to increase patient autonomy and function. These paradigms were based on a series of identified differences between the two syndromes (Table 3). However, in recent years it has become apparent that many of those differences are not so clear-cut. The result has been an emerging model based on a multidisciplinary and multimodal management of both patient populations. Therefore, pharmacological, physical, psychological or behavioural treatments are all indicated as part of comprehensive pain management in FGID.

\section{PHARMACOLOGICAL APPROACH}

Pharmacotherapy may play an important role for targeting specific functional disorders. 'Antispasmodic' drugs are most frequently used to treat pain symptoms in FGID, even though a clear relationship between pain and gut motility has not been firmly established. However, in view of the cholinergically mediated gastrocolonic response, the patient with recurrent abdominal pain after meals may benefit from an anticholinergic agent before meals (ie, 10 to $20 \mathrm{mg}$ dicycloverine $30 \mathrm{mins}$ before meals). Other antispasmodic drugs, such as calcium channel blockers, peppermint oil, naloxone and selective serotonin and cholecystokinin antagonist, have been proposed but require more clinical trials before acceptance (15).

Small doses of acetominophen may be useful in the short term while narcotics are not particularly encouraged (14). Whenever opioids are indicated for the pharmacological treatment of pain in FGID, the guidelines issued by the College of Physicians and Surgeons in the Province of Alberta are recommended (Table 4) (16).

Presently, neither the medical literature nor clinical experience support long term opioid use for patients with chronic nonmalignant pain. There are no adequate controlled trials of these drugs. The data appear to support the use of empirical therapeutic trials in selected patients, followed by carefully monitored long term therapy in those who benefit (17). Specifically, patients 
with a history of alcoholism or drug addiction, psychiatric disorders or somatization are particulary poor candidates for opioid trials.

Psychopharmacological agents such as antidepressants and anxiolytics seem to be effective in some patients. Central analgesia, anticholinergic action on the gut and relief of depression or anxiety may provide symptom remission in FGID (1). Tricyclic antidepressants and fluoxetine are often indicated in chronic pain management because of their brain serotoninergic action. They should be started in small doses (eg, 50 to $75 \mathrm{mg}$ amitriptyline at bedtime, $20 \mathrm{mg}$ fluoxetine in a single, daytime dose) with a gradual increase to effective and tolerated therapeutic levels. However, recent trials suggest that tricyclic antidepressants are more effective analgesics than specific serotonin-reuptake inhibitors (18). Benzodiazepine-type anxiolytics are occasionally helpful to relieve episodes of stress-related symptom flares. Their long term use and combination with anticholinergic drugs are not recommended (15).

\section{NONPHARMACOLOGICAL APPROACHES}

Physical therapy may play an important role for pain management in FGID. Modalities such as heat, cold, soft-tissue massage and transdermal electrical stimulation (TENS) can aid in decreasing or controlling pain. Exercise programs are implemented to correct secondary dysfunctions. Patient education in this context may enhance the patients' coping strategies with chronic disease, improve functional status and prevent excessive stress on both the involved and noninvolved body structures (19).

Among physical therapies, acupuncture has been used in chronic benign pain. Although its mechanism of action is still unclear, acupuncture plays a neuromodulating role in the mentioned stages of pain production (20).

Whenever psychosocial stressors are predominant, psychotherapy may be useful in diminishing their role in the pathogenesis of FGID symptomatology.

TABLE 5

Multidisciplinary pain centre

Clarify the diagnosis. Review medical records and the need for further diagnostic studies or invasive procedures

Improve pain control (eliminate pain if possible) through physical therapies:

Help the patient to be more comfortably active

Promote the use of alternative modalities other than potent medications

With individually structured exercise programs, reduce the patient's fear of reinjury

Teach proper body mechanics and postural awareness

Evaluate limitations and restrictions

Improve psychological functioning:

Define and address psychosocial issues influencing the chronic pain syndrome

Relieve drug dependency

Treat depression and its frequently associated insomnia

Address primary and secondary gains from pain

Assess family system

Strengthen support network (eg, personal, family and community)

Provide access to occupational and vocational rehabilitation and any other significant health care personnel, and resolve disability when possible

Communicate with the patient's referring physician via discharge summary, telephone or personal meetings to obtain any information that will assist in the continued management of the patient

Reduce inappropriate use of the health care system

Decrease the cost of medical care associated with chronic pain syndrome

Reproduced with permission from reference 22

Although beneficial in some cases, psychoanalytic psychotherapy can be time-consuming and costly (21). The techniques proposed by behavioural psychologists appear efficacious management tools in dealing with chronic and intractable pain syndromes. Behavioural treatments are mainly intended to modify an abnormal illness behaviour. This behaviour is defined as "the persistence of a maladaptive mode of experiencing, perceiving, evaluating and responding to one's own health status, despite the fact that a doctor has provided a lucid and accurate appraisal of the situation and management to be followed (if any), with opportunities for discussion, negotiation and clarification based on adequate assessment of all relevant biological, psychological and cultural factors" (21).

Behavioural techniques include relaxation response training, autogenic training, hypnosis and biofeedback, with the contribution of some of the pharmacological (eg, antidepressants) and physical (eg, massage, TENS) treatments previously mentioned. Relaxation response and autogenic training lower sympathetic nervous system activity and produce skeletal muscle re- laxation. Because of their simplicity, they are the primary treatment in the behavioural approach (1).

Hypnosis may reduce pain perception in the gut, particularly in patients without associated psychopathological abnormalities.

In biofeedback, skeletal muscle activity and other physiological functions are monitored by audio or visual instruments. The patients use this information to achieve a general state of relaxation or to gain control over usually unconscious physiological functions.

All those noninvasive methods may be performed by psychologists, behaviourally trained nurses, technicians and physicians. The choice of treatment depends on cost and availability (1).

The behavioural approach may help motivated patients to reduce anxiety and maladaptive illness behaviours. Productive behaviours can be restored by those treatments, which finally enhance pain tolerance (21).

Whenever pain and disability appear refractory to simple pharmacological interventions and basic counselling by the treating physician, FGID patients may be re-evaluated and managed by a 
multidisciplinary pain centre. The underlined goals are reported in Table 5 (22).

\section{SUMMARY}

Pain is a common feature in FGID. An abnormally low visceral sensory threshold, as well as a number of central, spinal and peripheral painmodulating abnormalities, have been proposed for this syndrome. Clinical

ACKNOWLEDGEMENTS: We acknowledge the Italian Association for Cancer Research, Milano, Italy, for funding Dr Vigano's Research Fellowship with the Palliative Care Program at Edmonton General Hospital, Edmonton, Alberta.

\section{REFERENCES}

1. Drossman DA, Thompson WG. The irritable bowel syndrome: review and a graduated multicomponent treatment approach. Ann Intern Med 1992;116:1009-16.

2. Snape WJ. Irritable bowel syndrome. In: Cohen S, Soloway RD, eds. Functional Disorders of the Gastrointestinal Tract. New York, Edinburgh, London, Melbourne: Churchill Livingston, 1987;4:59-68.

3. Mayer EA, Raybould H. Role of neural control in gastrointestinal motility and visceral pain. In: Snape WJ Jr, ed. Pathogenesis of Functional Bowel Disease. New York: Plenum Medical Book Co, 1989:13-35.

4. Costantini M, Sturniolo GC, Zaninotto G, et al. Altered esophageal pain threshold in irritable bowel syndrome. Dig Dis Sci 1993;38:206-12.

5. Bradette M, Delvaux M, Stautmont G, et al. Evaluation of colonic sensory thresholds in IBS patients using a barostat. Definition of optimal conditions and comparison with healthy subjects. Dig Dis Sci 1994;39:449-57.

6. Sorgensen LS, Bach FW, Christiansen $\mathrm{P}$, et al. Decreased cerebrospinal fluid $\beta$-endorphin and increased pain sensitivity in patients with functional abdominal pain. Scand J Gastroenterol 1993;98:763-6. aspects of pain associated with irritable esophagus, functional dyspepsia, biliary dysmotility, IBS and proctalgia fugax have been reviewed. Because of its unclear pathophysiology, pain expression is the main target for the successful assessment and management of symptomatic FGID.

The sensory, cognitive and affective components of pain intensity expression need to be addressed in the context of a good physician-patient

7. Song JY, Merskey H, Sullivan S, et al. Anxiety and depression in patients with abdominal bloating. Can J Psychiatry 1993;38:475-9.

8. Creed F, Craig T, Farmer R. Functional abdominal pain, psychiatric illness, and life events. Gut 1988;29:235-42.

9. Drossman DA, Leserman J, Nachman $G$, et al. Sexual and physical abuse in women with functional or organic gastrointestinal disorders. Ann Intern Med 1990;113:828-33.

10. Whitehead WE, Bosmajian L, Zonderman AB, et al. Symptoms of psychologic distress associated with irritable bowel syndrome. Comparison of community and medical clinic samples. Gastroenterology 1988;95:709-14.

11. Ouyang A. Chest pain, esophageal spasm, and other functional disorders of the esophagus. In: Cohen S, Soloway RD, eds. Functional Disorders of the Gastrointestinal Tract. New York, Edinburgh, London, Melbourne: Churchill Livingston, 1987;1:1-16.

12. Thompson WG. Functional dyspepsia. In: Thompson WG, ed. The Irritable Gut. Functional Disorders of the Alimentary Canal. Baltimore: University Park Press, 1979;12:153-72.

13. Thompson WG. Proctalgia fugax. In: Thompson WG, ed. The Irritable Gut. Functional Disorders of the Alimentary Canal. Baltimore: University Park Press, 1979;10:125-30.

14. Turk DC, Fernandez E. Pain: a cognitive-behavioural perspective. In: Watson M, ed. Cancer Patient Care Psychosocial Treatment Methods. Cambridge: The British Psychological Society \& Cambridge University Press, 1991:1544.

15. Pattee PL, Thompson WG. Drug rapport. A multidisciplinary team approach is ideal for the smaller subset of patients with severe and disabling symptoms. Although pharmacotherapy may target specific functional disorders, the role of behavioural techniques and psychotherapy appears much more important for pain management in FGID. Functional performance and quality of life improvement, rather than pain intensity, are the main therapeutic goals in these patients.

treatment of the irritable bowel syndrome. Drugs 1992;44:200-6.

16. College of Physicians and Surgeons of Alberta. Guidelines for management of chronic non-malignant pain. February 1993.

17. Portenoy RK. Opioid therapy for chronic nonmalignant pain: current status. In: Fields HL, Liebeskind JC, eds. Progress in Pain Research and Management. Seattle: IASP Press, 1994;16:247-87.

18. Max MB. Antidepressants as analgesics. In: Fields HL, Liebeskind JC, eds. Progress in Pain Research and Management. Seattle: IASP Press, 1994;15:229-46.

19. Yeh C, Shiell M, Lemke J, Volpe M. Physical therapy: evaluation and treatment of chronic pain. In: Aronoff GM, ed. Evaluation and Treatment of Chronic Pain, 2nd edn. Baltimore: Williams \& Wilkins, 1992;21:285-90.

20. Ng LKY, Katims JJ, Lee MHM. Acupuncture: a neuromodulation technique for pain control. In: Aronoff GM, ed. Evaluation and Treatment of Chronic Pain, 2nd edn. Baltimore: Williams \& Wilkins, 1992;22:291-8.

21. Pilowsky I. Abnormal illness behavior (dysnosognosia) and the management of chronic nonmalignant pain. In: Aronoff GM, ed. Evaluation and Treatment of Chronic Pain, 2nd edn. Baltimore: Williams \& Wilkins, 1992;33:409-15.

22. Aronoff GM, McAlary PW. Pain centers: treatment for intractable suffering and disability resulting from chronic pain. In: Aronoff GM, ed. Evaluation and Treatment of Chronic Pain, 2nd edn. Baltimore: Williams \& Wilkins, 1992;34:416-29. 


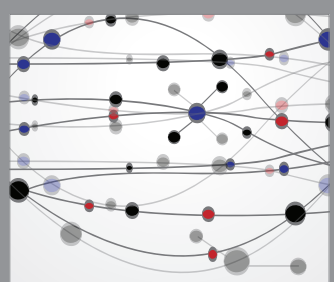

The Scientific World Journal
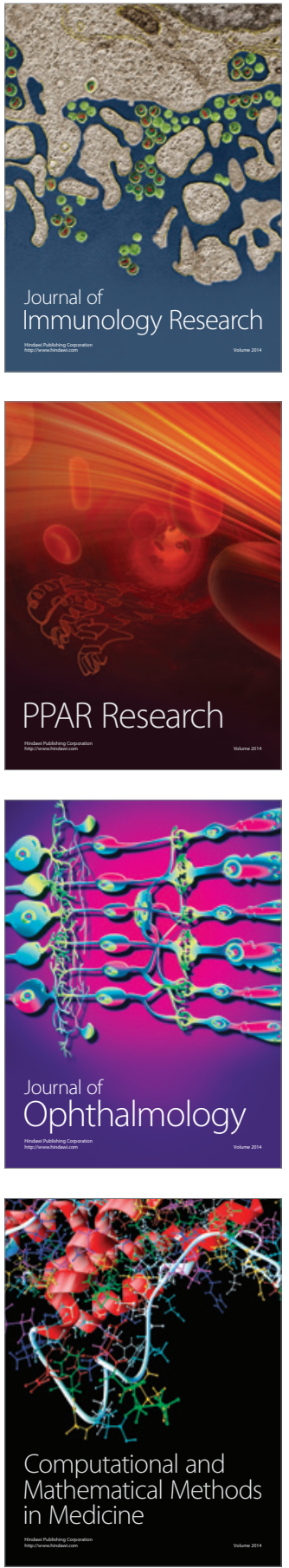

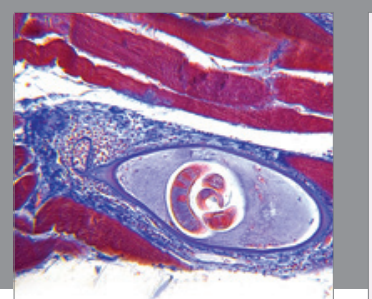

Gastroenterology Research and Practice

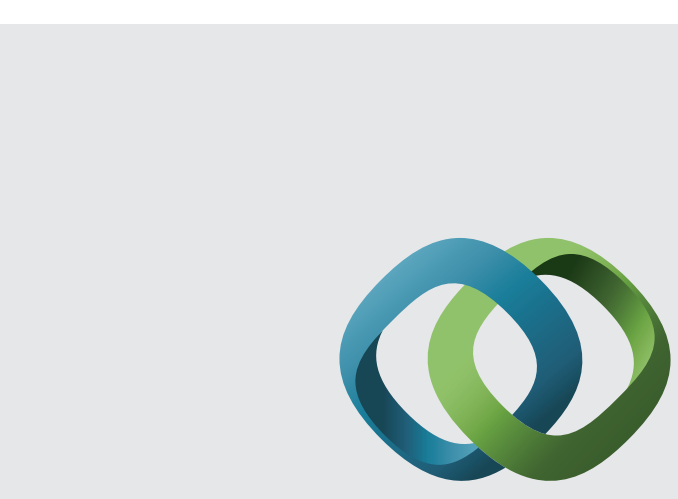

\section{Hindawi}

Submit your manuscripts at

http://www.hindawi.com
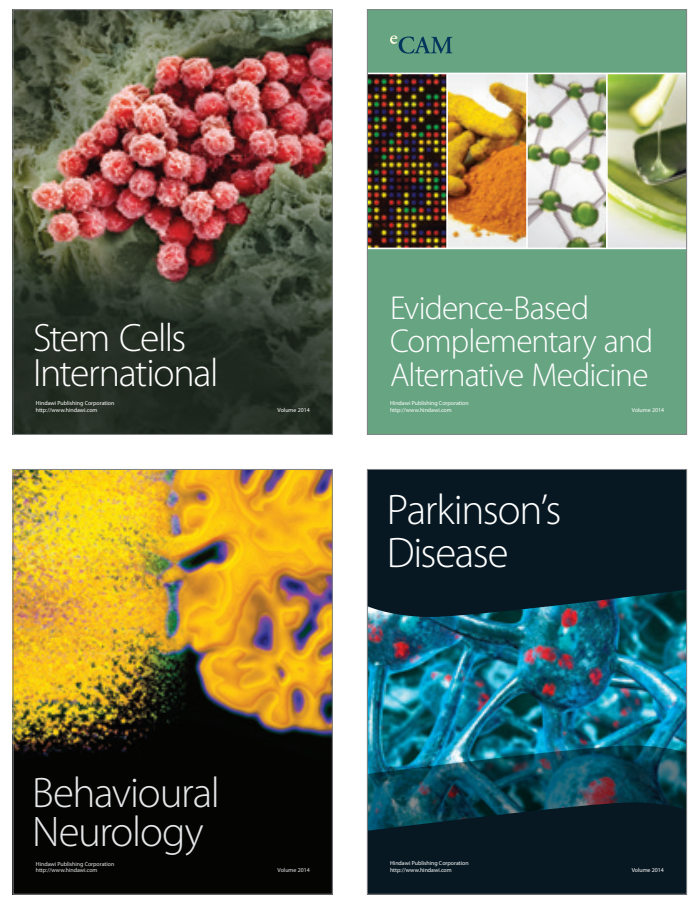
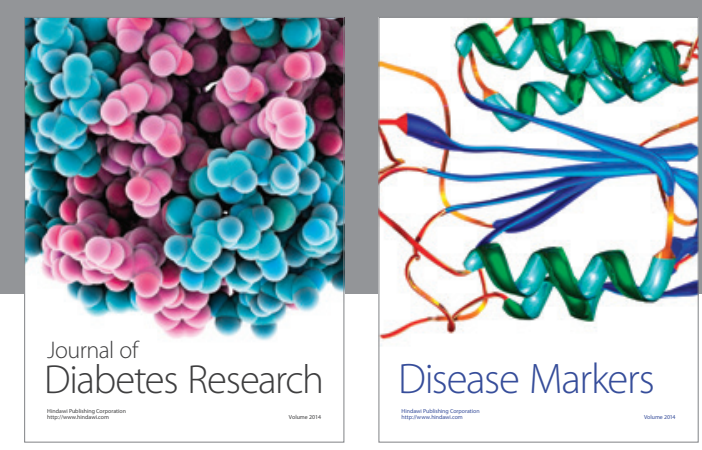

Disease Markers
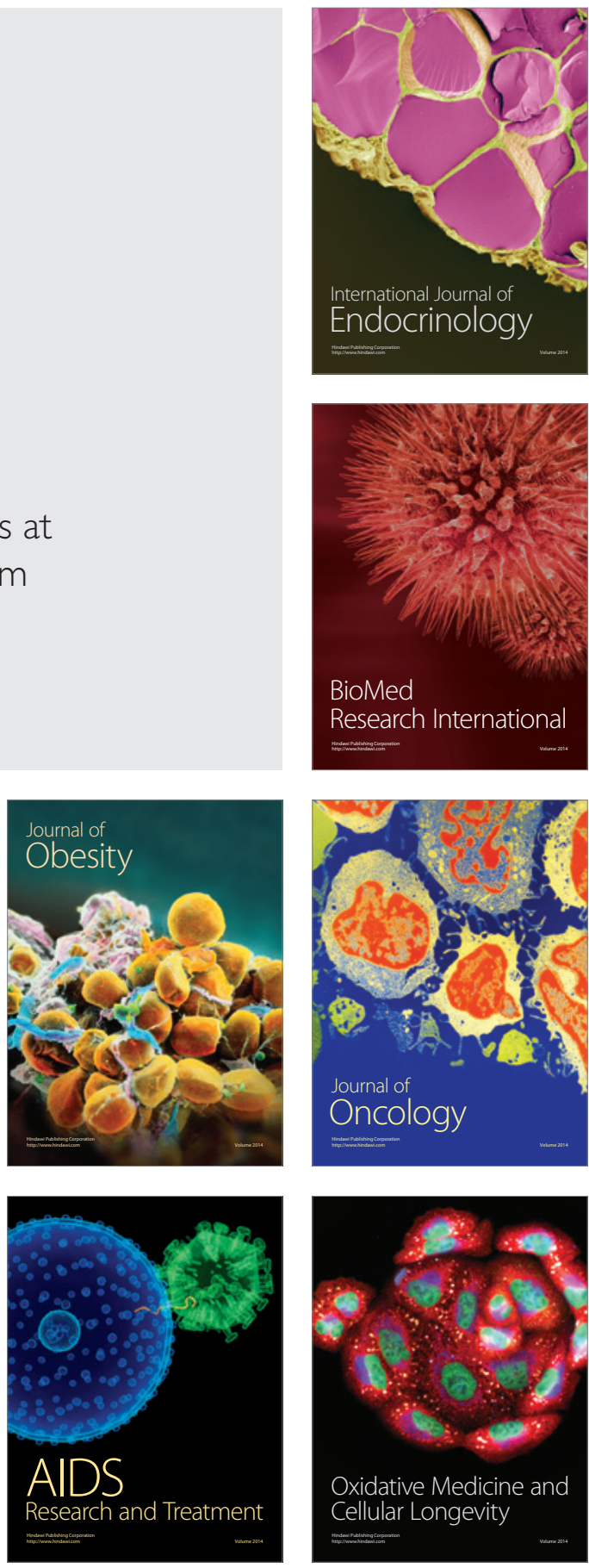